\title{
АРХЕОЛОГИЯ
}

Щапова Ю.Л.

DOI: 10.7256/2222-1972.2015.5.17303

При иитировании этой статьи сноска на доі обязательна

\section{О хронологии и периодизации археологической эпохи}

Аннотаиия. В статъе представлена модель хронологии и периодизаиии археологической эпохи, в основу которой положены эвристически найденные ряд и числа Фибоначчи, которые являются конкретным математическим выражением золотого сечения. Обрашение к ряду Фибоначчи потребовало уточнения структуры археологической эпохи - археологических субэпох, периодов, фаз, узловых моментов, а также всего логико-понятийного аппарата и терминологии (с дефиничией терминов). Модельная хронология и периодизачия археологической эпохи была соотнесена с хронологией общепринятой «системы трех веков» и верифицирована с хронологией и периодизаиией соответствующего отрезка времени информачионно-кибернетической модели. Первые две модели надежно (коэффициент связи $f=0,57)$ характеризуют эволюиию и историю одного и того же организма археологической эпохи. Модельная хронология и периодизачия выигрывает за счет соответствия общим законам развития, большей полноты, точности, простотъ, перспектив и комбинаторных возможностей. Важнейшие результаты применения модели хронологии и периодизачии археологической эпохи для ее изучения: эволючионные прочессы в археологической эпохе - челостное явление, которое содержит в себе археологические субэпохи; явной частью археологической субэпохи является эволюиионная триада - возникновение (становление) - расчвет - умирание (инволючия) - со скрытыми фазами, ее предваряюшими и завершаючими. Оиифрованная хронология и периодизация позволяет обрабатьвать новую не вербальную, а числовую информачию, изучая и сравнивая не только абсолютную и относительную продолжительность, но и кратность «веков», археологических субэпох и периодов и т. д. Очифрованная хронология и периодизачия помогла увидеть гармонию в структуре археологической эпохи, ее функииях и динамике, строго, как показывают дальнейшие исследования, соответствуюшую всеобщей гармонии мироздания.

Ключевые слова: археологическая эпоха, археологическая субэпоха, ряд Фибоначчи, числа Фибоначчи, хронология, периодизачия, «золотое сечение», археологчческая культура, материальная культура, мультидисииплинарность.

Abstract. This article reviews the model of chronology and periodization proposed for archaeological epochs, which is based on the heuristically-established Fibonacci sequence and numbers that are the concrete mathematical expression of the "golden ratio". The use of the Fibonacci sequence required the overall clarification of the structures of archaeological epochs: archaeological sub-epochs, periods, phases, nodal moments, as well as of its logical-conceptual apparatus and terminology (with term definitions) in general. The model chronology and periodization of archaeological epochs was correlated to the chronology of the accepted "system of three centuries" and verified with the chronology and periodization of the corresponding time interval of the informational-cybernetic model. The first two models reliably (the coupling coefficient $f=0.57)$ describe the evolution and history of one and the same organism - of an archaeological epoch. The model chronology and periodization gains authority because it corresponds with the general laws of development, better completeness, precision, simplicity, perspective, and combination possibilities. The most significant results derived from applying the model of chronology and periodization of an archaeological epoch for its study are: evolutionary processing within an archaeological epoch - a coherent phenomenon that contains in itself archaeological sub-epochs; the visible part of an archaeological sub-epoch is the evolutionary triad - genesis (becoming) - flowering - dying (involution) - with hidden phases preceding and succeeding it. Digitalised chronology and periodization allow to process new non-verbal, but numerical information, studying and comparing not only the absolute and relative continuances, but also the multiplicity of "centuries", archaeological epochs and periods, etc. Digitalised chronology and periodization has aided to see the harmony within the structures of archaeological epochs, their functions and dynamics, strictly (as following studies have shown) corresponding to the general harmony of universe.

Key words: archaeological epoch, archaeological sub-epoch, Fibonacci sequence, Fibonacci numbers, chronology, periodization, "golden ratio", archaeological culture, material culture, interdisciplinarity. 


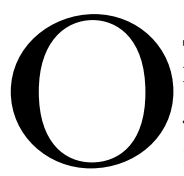
дин из первых вариантов модели хронологии и пеоиодизации археологической әпохи был представлен международному научному археологическому сообществу в 2001 г. [1]. Идеи той статьи были положены в основу общей концепции археологической эпохи (далее: АЭ; это новое понятие, обозначающее отрезок времени, в течение которого сформировался ее субъект, все предковые формы первобытного человека, история которого восстанавливается по археологическим источникам). Первоначально модель называлась общей моделью хронологии и периодизации АЭ, некоторое время - фибоначчиевой моделью хронологии и периодизации археологической эпохи (ФМАЭ). (Работа над моделью продолжается: она верифицирована, соотнесена с информационно-кибернетической моделью более крупного масштаба и апробирована на ряде примеров изучения и реконструкции тех исторических процессов, которые восстановлены по археологическим данным и в которые были вовлечены люди с момента их возникновения $[2 ; 3 ; 4 ; 5 ; 6]$.)

Идея ФМАЭ проста. Она представляет собой соотнесение ряда и чисел Фибоначчи (далее - РФ и ЧФ) с хронологией и периодизацией АЭ. Настоящее имя Фибоначчи - Леонардо да Пизано $(1170 / 1180$ - 1228/1240). Он знаменит тем, что ввел в европейскую математику арабские числа, создал начала вычислительной математики и прославившую его последовательность чисел (около 1200 г.).

В начало этой целочисленной последовательности он поставил две единицы. Каждый следующий ее член - сумма двух предыдущих: 1 , $1,2,3,5,8,13,21,34,55,89,144,233,377,610$, $987,1597,2584,4181,6765$ и т. д. Начиная с пятого члена РФ подчиняется «золотому сечению»1,618 (1,61 или 1,62). «Золотое сечение»- оно же гармоническое деление отрезков в крайнем и среднем отношении или «золотая пропорция»известно со школьных лет [7; 8; 9; 2]. Понятие, термин и модель, в частности, должны иметь дефиницию, т. е. быть описаны и определены настолько, чтобы «по определению» можно было понять, о чем идет речь. Модель в широком смысле - это аналог объекта, процесса или явления («оригинала» данной модели), любой его образ - условный, физический, мысленный. В настоящей статье хронология и периодизация археологической эпохи представлены в виде моделей словесных (вербальных), математиче- ских и графических. Всякая модель, развиваясь, должна превратиться в основу теории соответствующей отрасли знания [10, 33-44].

Подобная перспектива требует уточнения дефиниций терминов, используемых в ее построении. АЭ как понятие и термин выделена недавно для обозначения целостного явления и целостного предмета исследования. Термином «эпоха» обозначен отрезок времени, в течение которого некое целостное явление возникло, развилось и завершилось. Прилагательное «археологическая» обозначает источники, из которого извлечена информация, раскрывающая содержание эпохи. Носители такой информации материальны: древности, или артефакты, элементы искусственной системы жизнеобеспечения, создаваемые человеком в начальные периоды своей истории. Археологическая эпоха, воспринимаемая как система, с одной стороны, структурно подчинена надсистеме - иерархически более высокому организму, если можно так сказать, таковым можно считать наиболее сложный компонент живого, - с другой стороны, ей должны быть подчинены подсистемы - организмы, иерархически менее важные. Такой подсистеме, структурно подчиненной системе АЭ, я дала название археологическая субэпоха (АСЭ). АСЭ - это некий аналог отделов каменного века и собственно «веков» в «системе трех веков». В полной АЭ семь АСЭ. Фаза - новая структурная единица следующего (по нисходящей) иерархического уровня. В каждой АСЭ три фазы: первая - скрытая, вторая - явная, третья - скрытая. Период - структурная единица нисходящего иерархического уровня. Период отмечен тире между соседними числами в РФ - это единица измерения эволюционных процессов с ускорением, равным «золотому сечению». АЭ объемлет 20 таких периодов, в АСЭ их 6,5 или 4 фазы (явная 3 - 2, первая скрытая $2-1$, третья скрытая - 1). Периодизация - это и разделение процесса на периоды (или этапы), и результат такого разделения, и вхождение в созданную ранее периодизацию, т. е. пополнение новыми данными результатов, полученных ранее. Периодизации АЭ - точнее, математическая модель хронологии и периодизации - построена на основе чисел и ряда Фибоначчи [2].

Археологическую хронологию и периодизацию традиционно рассматривают как «систему трех веков», где каменному веку отведено около 2,8 млн лет, всем остальным - энеолиту, бронзовому и железному векам - чуть более 


\section{Исторический журнал: научные исследования № 5 (29) • 2015}

DOI: $10.7256 / 2222-1972.2015 .5 .17303$

Таблича 1

Хронология, периодизация и наименования археологической эпохи (сопоставление моделей)

\begin{tabular}{|c|c|c|c|}
\hline \multicolumn{2}{|c|}{ Хронология и периодизация (в тысячах лет) } & \multicolumn{2}{|c|}{ Наименования «веков» и отделов каменного века } \\
\hline Модельная & Общепринятая & Модельная АСЭ & Общепринятая номенклатура \\
\hline $2584-1597-987-610$ & $2800-800(600)$ & археолит & олдувай \\
\hline $610-377-233-144$ & $600-140$ & нижн. палеолит & ашель \\
\hline $144-89-55-34$ & $140-40$ & средн.палеолит & мустье \\
\hline $34-21-13-8$ & $40-10$ & \multicolumn{2}{|c|}{ верхний палеолит } \\
\hline $8-5-3$ & $10-8$ & неолит & мезолит \\
\hline & $8-5$ & неолит & неолит \\
\hline & $5-3$ & неолит & энеолит \\
\hline $3-2-1$ & $3-1$ & \multicolumn{2}{|c|}{ бронзовый век } \\
\hline 1 до н. Э. - 1 н. э. & 1 до Н. Э. - 1 н. э. & \multicolumn{2}{|c|}{ железный век } \\
\hline
\end{tabular}

Данные, приведенные в первых двух колонках, соответствуют хронологии и периодизации материальной культуры.

6 тыс. лет [11]. Сравним модельную хронологию и периодизацию АЭ, построенную согласно РФ, с общепринятой (см. таблицу 1$)$.

Обе модели хронологии и периодизации построены в одном масштабе времени (единица счета времени - одна тысяча лет). Более того, одинаково названы три строки, рубежные даты которых близки. Различаются они немного: например, в модельной периодизации 7 строк, в общепринятой - 9. В модельной периодизации строки одинаково соответствуют субэпохам, в традиционной - векам или отделам каменного века и бронзовому и железному векам в целом. Изначальное деление АЭ на периоды в модельной периодизации отсутствует в общепринятой периодизации. Продолжительность АЭ оценена по-разному: продолжительность общепринятой около трех миллионов лет, соответствующий отрезок в модельной равен 2586 (к 2584 тыс. лет от начала АЭ нужно приплюсовать 2 тыс. лет н. э.). Общепринятая хронология и периодизация более свободные и более дробные (мезолит и энеолит выступают как самостоятельные явления). Кроме того, в общепринятой системе хронологические границы округлены, в модельной они рассчитаны более точно. Хронологическая модель оказывается менее подробной, но более жесткой и строгой. Путем расчета установлено, что очевидную связь обеих хронологий выражает коэффициент $\mathrm{f}=0,57$. Это хороший показатель, свидетельствующий о том, что обе хронологии описывают историю одного и того же организма, в данном случае - АЭ.

Согласно общепринятому мнению, господствующая материальная культура, замещающая предыдущую, заметна в культурном облике предыдущей в виде некоего «забегания вперед», а в облике последующей - в виде своего рода «пережитка». Подобные «взаимоотношения» археологических культур повторяются настолько регулярно, что предшествование-замещениепереживание можно было бы считать признаками трех вариантов «взаимоотношений». Из истории науки следует, что смена и замещение культур были замечены намного раньше, чем переживание и тем более предшествование и забегание. Согласно ФМАЭ, скрытая фаза становления АСЭ может соответствовать забеганию, скрытая фаза инволюции - переживанию археологической культурой своего времени. Таким образом, очевидную и обязательную смену и замещение археологических культур сопровождают менее очевидные, но столь обязательные предшествование и переживание. Степень очевидности - видимо, достаточное основание, для того чтобы замещение культур считать явным признаком или фазой, а предшествование и переживание - латентными (скрытыми) признаками или фазами эволюции археологических культур. Эволюционный процесс как нечто целостное давно и успешно делят на три части: возникновение (становление) - расцвет - умирание (инволюция). Взятые вместе, они представляют собой незыблемую эволюционную триаду.

Работа с моделью позволила получить новое знание: расширить область приложения триады до уровня 6765 тыс. лет, выявить актуальность триады фаз (скрытая (становление) - явная - скрытая (инволюция)) для всех без исключения АСЭ, подразделить на периоды сами фазы и каждую АСЭ, а также выделить, согласно с РФ, АСЭ археолита. Все это позволило изменить хронологические границы эпох (см. таблицу 2). 
Археология

DOI: $10.7256 / 2222-1972.2015 .5 .17303$

Таблича 2

Макроструктура АЭ и АСЭ (в тыс. лет)

\begin{tabular}{|c|c|c|c|}
\hline Скрытая фаза становления & Явная фаза эволюции & Скрытая фаза инволюции & Число периодов \\
\hline $6765-4181-2584$ & $2584-1597-987-610$ & $610-377$ & $6=2+3+1$ \\
\hline $1597-987-610$ & $610-377-233-144$ & $144-89$ & $6=2+3+1$ \\
\hline $377-233-144$ & $144-89-55-34$ & $34-21$ & $6=2+3+1$ \\
\hline $89-55-34$ & $34-21-13-8$ & $8-5$ & $6=2+3+1$ \\
\hline $21-133-8$ & $8-5-3$ & $3-2$ & $5=2+2+1$ \\
\hline $5-3$ & $3-2-1$ & $1-0$ & $4=1+2+1$ \\
\hline $2-1$ & $1-0-1$ & $1-2$ н. э. & $4=1+2+1$ \\
\hline$\Xi=12$ периодов & $\Xi=18$ периодов & $\Xi=7$ периодов & Итого $\Xi=37$ \\
\hline
\end{tabular}

Хронология, продолжительность и кратность АЭ и АСЭ (в тыс. лет)

Таблича 3

\begin{tabular}{|c|c|c|}
\hline Хронология и периодизация АСЭ & $\begin{array}{c}\text { Продолжительность АСЭ } \\
\text { (в тыс. лет) }\end{array}$ & $\begin{array}{r}\text { Ее коэффициент } \\
\text { к предыдущей АСЭ } \\
\end{array}$ \\
\hline $6765-4181-\mathbf{2 5 8 4}-\mathbf{1 5 9 7}-\mathbf{9 8 7}-\mathbf{6 1 0}-377$ & 6388 & $4,2^{*}$ \\
\hline $1597-987-\mathbf{6 1 0}-\mathbf{3 7 7}-\mathbf{2 3 3}-\mathbf{1 4 4}-89$ & 1508 & 4,2 \\
\hline $377-233-144-89-55-34-21$ & 356 & 4,2 \\
\hline $89-5 \overline{5-34-21-13-8-5}$ & 84 & 4,2 \\
\hline $21-13-8-5-3-2$ & 19 & 4,2 \\
\hline $5-3-2-1-0$ & 5 & 3,8 \\
\hline 2-1-0-1-2 н. э. & 4 & 1,25 \\
\hline$\Xi_{\text {периодов }=37}$ & $\Xi$ тыс. л. $=8364$ & \\
\hline
\end{tabular}

Жирным прямым шрифтом выделены метакультуры семи субэпох. Тонким курсивом - скрытые фазы становления субэпох, подчеркнутым тонким курсивом выделен период с материально-производственной доминантой, обычным шрифтом - скрытые фазы инволюции субэпох. * означает коэффициент по отношению к доархеологической субэпохе, начало которой датировано, согласно модели, 28656 тыс. лет.

Коль скоро отрезки времени, записанные арабскими цифрами, можно складывать, вычитать, делить и т. д., то можно сравнивать не только абсолютную и относительную продолжительность, но и кратность «веков», АСЭ и периодов. Начнем расчетные процедуры с общепринятой системы. Путем вычитания из большего меньшего можно получить ряд чисел: $2200-460-100$ $30-2-3-2-2-2$. И, разделив предыдущее число на следующее, найдем пропорциональный ряд: $4,8-4,6-3,3-15-0,7-1,5-1-1$. Если не считать двух средних коэффициентов (15 и 0,7 ), стоящих особняком (речь идет о времени: верхний палеолит - мезолит - неолит), то общая тенденция изменений продолжительности этапов АЭ и коэффициента (от большего к меньшему) очевидна. Рассчитав таким же образом продолжительность этапов АЭ, согласно модели, получим ряд чисел и пропорций (см. таблицу 3 , столбцы второй и третий). Эти расчеты сделали заметными пропорциональность и общий порядок, в котором роль «золотого сечения» очевидна на протяжении почти всего каменного века АЭ: коэффициент 4,2 есть не что иное, как «золотое сечение» в кубе, т. е. 1,618
Роль «золотого сечения» для бронзового и железного веков не столь очевидна. Ускорение әволюционных процессов в бронзовом веке выше $(3,8)$ «золотого сечения» $1,618^{2}(2,12)$, а в железном оно ниже основного значения $(1,25$ против 1,618$)$. Столь яркий упорядочивающий математический компонент в хронологии АЭ никогда ранее не удавалось заметить.

Другими словами, эволюция, гармоничная для АЭ почти на всем ее протяжении, утрачивая присущую ей гармонию, наращивает скорость в течении последних десяти тысяч лет (см. две нижние ячейки среднего столбца). Бронзовый и железный века обособлены на этот раз иным способом. В общем контексте эволюции АЭ это могло бы означать появление большего числа более сильных факторов, влияющих на эволюционный процесс обеих АСЭ.

Вместе с тем очевидно, что сравниваемые модели хронологии АЭ объемлют процессы макросемантического масштаба, время которых измеряется в тысячелетиях. Однако, несмотря на единство экспериментальной основы, из их сравнения следует, что не зависящая от археологического контекста и подчиняющаяся «золото- 


\section{Исторический журнал: научные исследования № 5 (29) • 2015}

DOI: $10.7256 / 2222-1972.2015 .5 .17303$

Таблииа 4

Синхронизированная макромодель периодизации археологической эпохи (в тыс. лет)

\begin{tabular}{|c|c|}
\hline археолит & $6765-4181-\mathbf{2 5 8 4}-\mathbf{1 5 9 7 - 9 8 7 - 6 1 0 - 3 7 7}$ \\
\hline нижний палеолит & 1597-987-610-377-233-144-89 \\
\hline средний палеолит & $377-233-\mathbf{1 4 4}-\mathbf{8 9}-\mathbf{5 5}-\mathbf{3 4}-21$ \\
\hline верхний палеолит & $89-\underline{55}-\mathbf{3 4}-\mathbf{2 1 - 1 3 - 8 - 5}$ \\
\hline неолит & $21-\underline{13}-8-5-3-2$ \\
\hline бронзовый век & $5-3-2-1-0$ \\
\hline железный век & $2-1-0-1-2$ \\
\hline
\end{tabular}

Жирным прямым шрифтом выделены метакультуры семи субэпох. Тонким курсивом - скрытые фазы становления субэпох, подчеркнутым тонким курсивом выделен период с материально-производственной доминантой, обычным шрифтом - скрытые фазы инволюции субэпох.

му сечению» математическая модель характеризует эволюцию АЭ как процесс гармонический и закономерный. Этого обстоятельства, на мой взгляд, достаточно, чтобы понять причину, по которой общепринятой хронологии и периодизации АЭ я предпочитаю ФМАЭ.

Однако нельзя не заметить, что моделирование позволило выделить различия, усиливающие несходство рассматриваемых моделей. Общепринятая система построена индуктивно, с учетом местных особенностей и в зависимости от археологического контекста. ФМАЭ построена дедуктивно и общо, единицы периодизации и числа, лежащие в ее основании, от археологического контекста не зависят. Более того, упорядоченность и гармонию («золотое сечение») можно считать генетическим свойством последней.

Как следует из таблицы 1 , материальная культура эволюционирует без переходных форм конец одной есть начало другой, - подтверждая тем самым эволюционный постулат, согласно которому ведущую роль в эволюции играло скачкообразное (сальтационное) видообразование. Перечень культур - ранний ашель, ашель, мустье и т. д. - мог бы служить примером следования такому постулату. Эта же таблица показывает, что сальтационная эволюция и развитие материальной культуры - это только явное, т. е. неполное, содержание эволюции и АЭ в целом, и АСЭ, и ее частей. Явное в общепринятой «системе трех веков» нередко становится самым важным - не доминантным, а единственно главным, что, как показывает таблица 2, и как показали дальнейшие исследования, является следствием информационной неполноты и несовершенства методологической природы археологического знания, использованного для построения такой модели [12, 65-68; 13].

Рассмотрим противоречие, возникшее из сравнения периодизации АЭ согласно ФМАЭ и собственно РФ. Весь РФ, актуальный по отноше- нию к АЭ, включает 20 периодов. Скрытая фаза становления всех АСЭ насчитывает 12 периодов, явная - 18, скрытая инволюции - 7. Итого полная периодизации АСЭ требует 37 периодов (таблица 2, нижняя строка). Очевидно, что хронология и периодизация АЭ должна быть организована так, чтобы 20 периодов, содержащихся в этом отрезке РФ, могли бы превратиться в 37 . Очевидно, что нужно удвоить число периодов. В моделировании это возможно. Объединив первые три колонки таблицы 2, получим новую таблицу. В ее первую колонку впишем полные строки с датами всех АСЭ, разделенных на три фазы (помечены разными шрифтами). Во втором столбце указана полная продолжительность соответствующих АСЭ, в последнем - коэффициент изменения полной продолжительности ACЭ (см. таблицу 3).

Синхронизируем эволюционные процессы и создадим таблицу 4.

Одного взгляда достаточно, чтобы заметить уникальность первых двух (6765 - 4181 - 2584) и двух последних $(0-1-2)$ одинарных периодов АЭ, далее - 29 сдвоенных и пяти строенных периодов (на уровнях 377, 89, 21, 5, 2 тыс. лет). Таким образом, эволюция и развитие АЭ - это параллельный самому себе семантически разномасштабный процесс. Семантический масштаб процессов помогает различать единицы измерения времени: мегасемантический масштаб измеряется в миллионах лет, макросемантический в тысячах лет, мезосемантический - в сотнях лет, микросемантический - в десятках лет. Мегасемантические процессы включают в себя геоглобальные процессы - становление Земли как космогонического тела и возникновение на ней органической жизни. Макросемантический уровень объемлет процессы планетарного масштаба - эволюцию производственной деятельности человека и процессы становления человека как носителя этой эволюции. Б. С. Шорников пред- 
лагает считать его филогенетическим или антропо-археологическим [14].

Столбцы из трех строк назовем узловыми моментами. Повторю, что их - пять: 377, 89, 21, 5,2 . По числу строк их должно было бы быть семь. Неполные два (на уровне 6765 и 1597 тыс. лет) фиксируют моменты возникновения Ноmо habilis и архантропов. Пять остальных фиксируют моменты возникновения палеоантропа (неандерталец и Homo sapiens primigenius), Homo sapiens, Homo sapiens-2, Homo sapiens-3 и человека современного. Последний этап эволюции человека современного - Homo modernus представляет Homo sapiens-4.

Процессы, измеряемые в тысячах тысяч лет, было бы правильнее называть антропологическими, чтобы отделять их от антропо-археологических или археологических, измеряемых в тысячах лет. Продолжая әту логику, я думаю, можно выделить процессы археологоисторические, измеряемые в столетиях и относящиеся к АСЭ бронзы и железа. Явная фаза таких событий завершается к концу первого тысячелетия н. э. События всего последующего времени следовало бы называть историческими. Вопрос - как называть ту эпоху и те процессы, в которые вовлечены современные народы, не знающие письменности, - остается для меня открытым. И еще одно добавление: процесс, измеряемый в единицах лет, можно было бы считать уникальным. Такое добавление позволило бы совокупный процесс эволюции и развития АЭ считать пентадой - очень гармоничным образованием.

Вернемся к таблице 4 . Из нее следует, что формирование АСЭ археолита и его начальная әволюция совпадают с появлением и становлением Homo habilis (на уровне 6765 тыс. лет). Более того, формирование каждой следующей АСЭ и ее начальная эволюция совпадают и с появлением, и со становлением ее носителя (субъекта, человека соответствующего уровня сложности [15]), и с узловыми моментами, указанными выше. Уровней сложности субъекта АСЭ, включая Homo habilis (6765 тыс. лет), должно быть также семь: архантроп возникает на уровне 1597 тыс. лет, палеантроп - 377 тыс. лет, Homo sapiens - 89 тыс. лет, Homo sapiens sapiens (в других терминах Homo sapiens-2) - 21 тыс. лет, человек современный - Homo modernus, или Homo sapiens sapiens sapiens, - 5 тыс. лет (в форме Homo sapiens-3), Homo sapiens-4 - 2 тыс. лет (см. две последние строки таблицы 4).
Таблица 4 сделала очевидным ранее неизвестный факт: каждая АСЭ проходит полностью свой закономерный, ничем не нарушаемый эволюционный путь от начала до конца (конца «в основном», т. е. за исключением возможных реликтовых форм).

Казалось бы, что, рассчитав коэффициент связи (сходства) обеих периодизаций и хронологий $(\mathrm{f}=0,57)$ и признав их принадлежность к истории одного и того же организма - в данном случае АЭ, - можно было бы закрыть тему. Однако именно коэффициент $(\mathrm{f}=0,57)$ и побудил меня вернуться к обеим хронологиям, прежде чем перейти к заключению. Главное различие их разная «длина»: 20 периодов против 37. На этом основании одну - общепринятую - хронологию можно было бы называть короткой, а другую - длинной. Приняв во внимание число периодов в строках, одну - традиционную хронологию - можно было бы называть узкой (в ней обозначены лишь начала и концы истории материальной культуры соответствующего отдела или «века» АЭ), другую - широкой. Кроме начала и конца истории материальной культуры соответствующего отдела или «века», в ней обозначены еще по две скрытые фазы - становления и инволюции АЭ. Фазы, которые я назвала скрытыми, действительно очевидны не всегда, однако не будучи названными, они давно были примечены, их скорее предвкушали как особый или частный случай. Тем не менее они, лишенные анализа, понимания и истолкования, оказались до сих пор вне поля зрения науки.

ФМАЭ, будучи мультидисциплинарной и необыкновенно наукоемкой, требовала для своей верификации столь же мультидисциплинарных данных, методов, подходов и теорий. Среди них оказались не только математика, антропология, техноценология, биология, генетика, биостратиграфия, социология, геронтологии и др. ФМАЭ обладает не только контрольной, но и прогностической силой по отношению к своим собственным подсистемам (пространственным и / или временным), а также по отношению к своей надсистеме - истории человечества независимо от вида источников, на основании которых формировались и формируются представления о ней.

ФМАЭ, сделавшую очевидными иерархическую организацию и нелинейное развитие АЭ, любой практикующий археолог, опираясь на чисто археологические данные, может использовать для культурно-исторической иден- 


\section{Исторический журнал: научные исследования № 5 (29) • 2015}

DOI: $10.7256 / 2222-1972.2015 .5 .17303$

тификации изучаемого им памятника. Археологические культуры, ставшие основой модели, были изучены в достаточной мере и могут быть использованы при изучении, по меньшей мере, двух ее качеств. Во-первых, это - скрытые фазы, на которые ФМАЭ заставила обратить внимание, изучить их и вписать в смысл АЭ, ее структуру и в общеисторический контекст. Во-вторых, в первый период скрытой фазы становления АЭ в целом и каждой АСЭ их доминантой является антропогенез, который приобрел особое значение для понимания общего смысла эпохи. Оказавшись в начале самой первой и каждой следующей строки (в таблице 4), он стал принципом их структуры, эволюции и развития. Главные смыслы слова «принцип», «princeps»- первый, главный, лучший, основной, крупнейший, особенно пригодный для чего-либо [16, 810].

Сам вывод, может быть, и не нов, он просто хрестоматиен: древний человек как представитель населения и носитель археологической культуры явно или по умолчанию, скрыто присутствует в каждом сочинении по археологии. Новизну предлагаемой формулировке придает акцент: сложность эволюционных процессов в материальной культуре, которая есть функция, аргументом которой является ее субъект, человек, уровень сложности организации которого первичен по отношению ко всей его деятельности.

Таким образом, построенная и выверенная ФМАЭ и ее числовая структура могут быть использованы для историко-культурной интерпретации получаемых новых данных как некий шаблон, ключ, образец или шкала времени (см. таблицу 4).
Еще большее впечатление возникает, когда строки ФМАЭ синхронизированы (таблица 5).

Таблииа 5

Шкала времени и культурно-историческая идентификация археологических данных

6765 - 4181-2584 - 1597-987 - 610 - 377 археолит

1597- 987-610-377-233-144-89 нижний палеолит 377-233- 144-89-55-34-21 средний палеолит

$89-55-34-21-13-8-5$ верхний палеолит

$21-13-8-5-3-2$ неолит

$5-\mathbf{3 - 2}-\mathbf{1}-0$ бронзовый век

2-1 - 0-1-2 н. э. железный век

Правила пользования шкалой просты: нужно найти место памятника на хронологической оси. В альтернативных случаях принадлежность памятника к субэпохе определяет уровень сложности «индустрии» материальной культуры.

Гуманитарный компонент мультидисциплинарного археологического целостным, внутренне гармоничным явлениям знания делает археологию наукой о дописьменной и бесписьменной истории человечества. Математика и естественнонаучный компонент придают археологии столь свойственные естественным наукам однозначность, точность, полноту, непротиворечивость, закономерность и гармонию.

Современная археологии, сохраняя верность своему источнику, расширила предмет исследования настолько, что рядом с археологией - наукой о древностях - формируется археология как наука о человеке, как о субъекте его древнейшей истории, восстанавливаемой по археологическим данным на уровне безымянных исторических процессов - материальных, социальных и духовных - производства и культуры.

\section{Библиография:}

1. Chthapova J. Chronologie générale et division en périodes des époques les plus anciennes // Actes du XIV-ème Congrès UISPP. Université de Liège, Belgique, 2-8 septembre, 2001. Liège: Université de Liège, 2003. P. 105-197.

2. Щапова Ю. Л. Археологическая эпоха: хронология, периодизация, теория, модель. М.: КомКнига, 2005. 189 с.

3. Щапова Ю. Л. Археологическая эпоха: содержание, структура, законы эволюции и развития // Труды III (XIX) Всероссийского археологического съезда. Т. ІІ. СПб.; М.; Великий Новгород: Новгородский технопарк, 2011. С. 360-361.

4. Гринченко С. Н., Щапова Ю. Л. Развитие Человечества, часть 3: кибернетическое и математическое моделирование // Труды II (XVIII) Всероссийского археологического съезда. Т. III. М.: Институт археологии РАН, 2008. С. 190-192.

5. Гринченко С. Н., Щапова Ю. Л. История Человечества: модели периодизации // Вестник РАН. 2010. № 12. С. 1076-1084.

6. Гринченко С. Н., Щапова Ю. Л. История Человечества: модели периодизации и их сравнительный анализ // Исследовано в России: электронный научный журнал. 2011. № 064. С. 865-885.

7. Уайлд Дж. Методы поиска экстремума. М.: Мир, 1967. 268 с.

8. Воробьев Н. Н. Числа Фибоначчи. М.: Наука, 1984. 144 с.

9. Щапова Ю. Л. Развитие, эволюция, Н-распределение и ряд Фибоначчи // Ценологические исследования. Вып. 13. Абакан: Центр системных исследований, 1999. С. 119-125.

10. Моисеев Н. Н. Экология человечества глазами математика. Человек, природа и будущее цивилизации. М.: Молодая гвардия, 1988. 304 с.

11. Археология: Учебник / Под ред. В. Л. Янина. М.: Издательство Московского университета, 2012. 604 с.

12. Щапова Ю. Л. Материальное производство в археологическую эпоху. СПб.: Алетейя, 2011. 235 с.

13. Подобина В. М., Савина Н. И., Макаренко С. Н., Костеша О. Н., Татьянин Г. М., Родыбин С. А., Стегний В. Н., Шарахов И. В., 
Лийницкая Т. А. Международный симпозиум «Эволюция жизни на земле» // Вестник Российского фонда фундаментальных исследований. 1998. № 2 (12). С. 16-27.

14. Шорников Б. С. Проблема идентификации, классификации и масштабной интерполяции в задачах оценки хроноэволюционной периодизации рядами Фибоначчи (Постановка естественнонаучной числовой диагностической задачи в системе 4М) // Щапова Ю. Л. Археологическая эпоха: хронология, периодизация, теория, модель. М.: КомКнига, 2005. C. $186-189$.

15. Мейен С. В. Принцип сочувствия. Размышления об этике и научном познании. М.: ГЕОС, 2008. 210 с.

16. Дворецкий И. Х. Латинско-русский словарь. М.: Русский язык, 1976. 1096 с.

\section{References (transliterated):}

1. Chthapova J. Chronologie générale et division en périodes des époques les plus anciennes // Actes du XIV-ème Congrès UISPP. Université de Liège, Belgique, 2-8 septembre, 2001. Liège: Université de Liège, 2003. P. 105-197.

2. Shchapova Yu. L. Arkheologicheskaya epokha: khronologiya, periodizatsiya, teoriya, model'. M.: KomKniga, 2005. $189 \mathrm{~s}$.

3. Shchapova Yu. L. Arkheologicheskaya epokha: soderzhanie, struktura, zakony evolyutsii i razvitiya // Trudy III (XIX) Vserossiiskogo arkheologicheskogo s"ezda. T. II. SPb.; M.; Velikii Novgorod: Novgorodskii tekhnopark, 2011. S. 360-361.

4. Grinchenko S. N., Shchapova Yu. L. Razvitie Chelovechestva, chast' 3: kiberneticheskoe i matematicheskoe modelirovanie // Trudy II (XVIII) Vserossiiskogo arkheologicheskogo s"ezda. T. III. M.: Institut arkheologii RAN, 2008. S. 190-192.

5. Grinchenko S. N., Shchapova Yu. L. Istoriya Chelovechestva: modeli periodizatsii // Vestnik RAN. 2010. № 12. S. 1076-1084.

6. Grinchenko S. N., Shchapova Yu. L. Istoriya Chelovechestva: modeli periodizatsii i ikh sravnitel'nyi analiz // Issledovano v Rossii: elektronnyi nauchnyi zhurnal. 2011. № 064. S. 865-885.

7. Uaild Dzh. Metody poiska ekstremuma. M.: Mir, 1967. $268 \mathrm{~s}$.

8. Vorob'ev N. N. Chisla Fibonachchi. M.: Nauka, 1984. $144 \mathrm{~s}$.

9. Shchapova Yu. L. Razvitie, evolyutsiya, N-raspredelenie i ryad Fibonachchi // Tsenologicheskie issledovaniya. Vyp. 13. Abakan: Tsentr sistemnykh issledovanii, 1999. S. 119-125.

10. Moiseev N. N. Ekologiya chelovechestva glazami matematika. Chelovek, priroda i budushchee tsivilizatsii. M.: Molodaya gvardiya, 1988. $304 \mathrm{~s}$.

11. Arkheologiya: Uchebnik / Pod red. V. L. Yanina. M.: Izdatel'stvo Moskovskogo universiteta, 2012. 604 s.

12. Shchapova Yu. L. Material'noe proizvodstvo v arkheologicheskuyu epokhu. SPb.: Aleteiya, 2011. $235 \mathrm{~s}$.

13. Podobina V. M., Savina N. I., Makarenko S. N., Kostesha O. N., Tat'yanin G. M., Rodybin S. A., Stegnii V. N., Sharakhov I. V., Liinitskaya T. A. Mezhdunarodnyi simpozium «Evolyutsiya zhizni na zemle» // Vestnik Rossiiskogo fonda fundamental'nykh issledovanii. 1998. № 2 (12). S. 16-27.

14. Shornikov B. S. Problema identifikatsii, klassifikatsii i masshtabnoi interpolyatsii v zadachakh otsenki khronoevolyutsionnoi periodizatsii ryadami Fibonachchi (Postanovka estestvennonauchnoi chislovoi diagnosticheskoi zadachi v sisteme 4M) // Shchapova Yu. L. Arkheologicheskaya epokha: khronologiya, periodizatsiya, teoriya, model'. M.: KomKniga, 2005. S. 186-189.

15. Meien S. V. Printsip sochuvstviya. Razmyshleniya ob etike i nauchnom poznanii. M.: GEOS, 2008. $210 \mathrm{~s}$.

16. Dvoretskii I. Kh. Latinsko-russkii slovar'. M.: Russkii yazyk, 1976. 1096 s. 